\title{
Characterization of Chromate Conversion Coating Formation and Breakdown Using Electrode Arrays
}

\author{
W. Zhang, ${ }^{\mathrm{a}, *}$ B. Hurley, ${ }^{\mathrm{b}}$ and R. G. Buchheit ${ }^{\mathrm{a}, * *, \mathrm{z}}$ \\ ${ }^{a}$ Department of Materials Science and Engineering and ${ }^{b}$ Department of Chemistry, The Ohio State University, \\ Columbus, Ohio 43210, USA
}

Chromate conversion coating (CCC) formation and breakdown was examined using 25 element $\mathrm{Al}$ wire electrode arrays. Arrays were interrogated using a multichannel analyzer capable of separately recording currents from each electrode. During CCC formation, electrodes exhibited a $30 \mathrm{~s}$ period of intense electrochemical activity characterized by large net currents. On any given element, net current polarity was found to be predominantly anodic, predominately cathodic, or mixed. After $30 \mathrm{~s}$, net currents decayed to small values, which remained small out to $300 \mathrm{~s}$ of exposure. Raman spectroscopy showed that $\mathrm{Cr}^{6+}$ concentrations in the coating continued to increase during this electrochemically quiescent period, suggesting continued CCC evolution. Conversion-coated arrays were subject to anodic potentiodynamic polarization in $0.5 \mathrm{M} \mathrm{NaCl}$ until all elements on the array exhibited coating breakdown and substrate pitting. Breakdown potentials were found to increase with coating time up to $120 \mathrm{~s}$, indicating anodic inhibition in CCC corrosion protection. Breakdown was found to be more difficult on electrodes that were net cathodes during coating formation. Results also showed that the $\mathrm{NaF}$ and $\mathrm{K}_{3} \mathrm{Fe}(\mathrm{CN})_{6}$ in commercial CCC bath formulations strongly contributed to coating corrosion resistance. Without $\mathrm{Fv}$, the $\mathrm{Al}$ surface passivated quickly during coating formation, and a nonprotective film formed. Without $\mathrm{Fe}(\mathrm{CN})_{3}^{6-}$, CCCs exhibited lower breakdown potentials.

(C) 2002 The Electrochemical Society. [DOI: 10.1149/1.1485774] All rights reserved.

Manuscript submitted July 5, 2001; revised manuscript received February 1, 2002. Available electronically June 12, 2002.

Chromate conversion coatings (CCCs) on $\mathrm{Al}$ alloys are very effective in protecting against localized corrosion and promoting paint adhesion. However, the high toxicity and carcinogenic effect of $\mathrm{Cr}^{6+}$, which is a main component in CCC processing chemistry, has resulted in increasingly strict regulations regarding its usage and waste disposal. Efforts have been made to develop environmentally friendly, alternative coating systems, but so far few have been able to match the performance of CCCs. Arguably, this is due to the lack of a complete understanding of CCC formation and corrosion protection mechanisms.

The structure and chemical composition of CCCs have been the subject of numerous studies. ${ }^{1-11}$ The findings of these studies show CCCs to be a mixture of chromium oxides, other components from coating bath, and components from substrate. Chromium is present in CCC as both $\mathrm{Cr}^{3+}$ and $\mathrm{Cr}^{6+}$, with $\mathrm{Cr}^{6+}$ predominantly in the outer layer. Several mechanisms have been proposed to explain the excellent corrosion protection provided by CCCs. Among them are the barrier layer protection mechanism, ${ }^{12,13}$ the bipolar membrane mechanism, ${ }^{14,15}$ and the active corrosion protection mechanism. ${ }^{3,11,16,17}$ Other studies have been carried out on the formation of CCCs. Commonly, CCC formation is described as a redox reaction between chromate ions and substrate metals. ${ }^{3,8,9}$ Chromate ions are reduced to nonsoluble chromium oxide, which forms on substrate as a protective layer. In accelerated chromium chromate coating formulations, $\mathrm{K}_{3} \mathrm{Fe}(\mathrm{CN})_{6}$ is present as an accelerator ${ }^{2,8,9,18,19}$ for the $\mathrm{Cr}^{6+} / \mathrm{Cr}^{3+}-\mathrm{Al}^{0} / \mathrm{Al}^{3+}$ redox couple. $\mathrm{NaF}$ is present as an activator ${ }^{3,8}$ that dissolves any air-formed surface film, and allows the conversion reaction to proceed with greater intensity than would otherwise be possible.

Although the chemistry and structure of CCCs have been investigated extensively, only a few studies have focused on the relationship between formation of CCCs and subsequent breakdown behavior in $\mathrm{Cl}^{-}$solutions under potential control. ${ }^{20,21}$ The functions of $\mathrm{K}_{3} \mathrm{Fe}(\mathrm{CN})_{6}$ and $\mathrm{NaF}$ in the coating bath have also been studied, but how these minor additions affect coating breakdown is not clear. CCC performance is usually assessed by salt spray or field exposure, but electrochemical impedance spectroscopy (EIS) has been used with increasing regularity in recent years. ${ }^{22}$ Anodic polarization methods have not been widely used to evaluate CCC breakdown

\footnotetext{
* Electrochemical Society Student Member.

** Electrochemical Society Active Member.

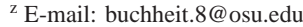

behavior, perhaps because chromate conversion coatings on largearea electrodes (area $\geqslant 1.0 \mathrm{~cm}^{2}$ ) do not usually show much improvement in pitting potential in concentrated chloride solutions. Improvements in pitting potentials of CCC-coated 2024-T3 have been reported in $0.1 \mathrm{M} \mathrm{Na} \mathrm{SO}_{4}+0.005 \mathrm{M} \mathrm{NaCl}$ solutions however. $^{20,21}$

In this study, a multichannel microelectrode analyzer (MMA) was used to monitor the electrochemical activity on aluminum electrode arrays during coating formation. The coatings were allowed to dry and were then subject to potentiodynamic polarization in $0.5 \mathrm{M}$ $\mathrm{NaCl}$ solution until breakdown was detected. The effects of coating time, $\mathrm{K}_{3} \mathrm{Fe}(\mathrm{CN})_{6}$, and $\mathrm{NaF}$ on coating formation and breakdown were studied using this approach. Using the MMA, it was possible to directly study the relationships between the coating formation process, as indicated by the current evolution, and coating breakdown. The results from these experiments shed new light on the $\mathrm{CCC}$ formation process and the relationship between CCC processing and bath chemistry. These findings may also provide some guidance to the development of chromate-free coating systems.

\section{Experimental}

Materials and electrode construction.-To study CCC formation and breakdown, aluminum wires, $0.5 \mathrm{~mm}$ diam, with a purity of $99.999 \%$ were used to build $5 \times 5$ electrode arrays. A photograph of the electrode array is shown in Fig. 1. The distance between two adjacent electrodes in a row or a column is around $1 \mathrm{~mm}$. At this distance, diffusion fields associated with individual electrode elements do not overlap and there is no chemical interaction between array elements during the coating formation process. Assuming diffusion coefficient of $5 \times 10^{-6} \mathrm{~cm}^{2} / \mathrm{s}{ }^{23}$ for ions in coating bath and a maximum coating time of $300 \mathrm{~s}$, the diffusion length can be estimated using

$$
L=(D t)^{1 / 2}
$$

The calculated diffusion length is $0.4 \mathrm{~mm}$, which is less than the distance between the electrodes in immediate neighboring rows or columns. During subsequent anodic potential scanning experiments in which individual electrode elements developed pitting, chemical interactions cannot be ruled out on the basis of a diffusion argument. However, pitting on an array appeared to occur randomly, that is, pitting of one element did not appear to accelerate or delay pitting of its immediate neighbors compared to the entire population of electrodes in the array. 


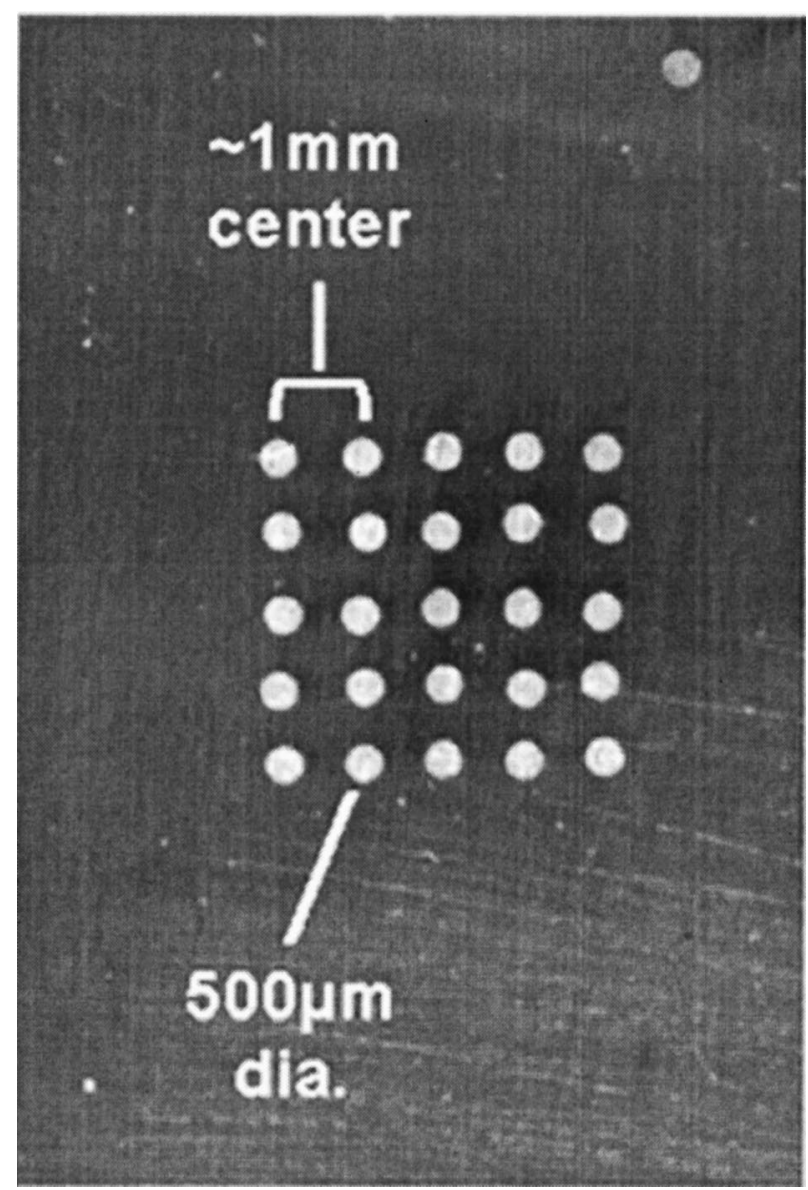

Figure 1. Photograph of electrode array used in this study.

Since these electrode segments are connected through zero resistance ammeters (ZRAs), it is necessary to estimate the ohmic resistance between adjacent electrodes. Using a solution provided by Newman for a disk electrode, ${ }^{24}$ the ohmic resistance between neighboring electrodes was calculated to be about $55 \Omega$ in $0.5 \mathrm{M} \mathrm{NaCl}$ and $140 \Omega$ in the coating bath.

It should be noted that similar experimental approaches have been used by Lunt et al. to study the interactions among localized corrosion sites on a $5 \times 5$ array of 316 stainless steel wires. ${ }^{25}$ Array-based studies have also been conducted by Tan to study the heterogeneous electrochemical processes on steel surfaces due to water droplet corrosion. ${ }^{26}$

All the chemicals used in the study were ordered from commercial vendors and were of reagent grade. The distilled water, with a resistivity of $18 \mathrm{M} \Omega \mathrm{cm}$, was used to make up all solutions.

Conversion coating and breakdown.-A model 900 MMA (Scribner and Associates, Southern Pines, NC) was used to monitor the current on each electrode during CCC formation and breakdown. The MMA was used to measure each electrode element in the array individually. During coating formation, the current on each electrode was measured on a separate, dedicated ZRA capable of measuring currents up to $1 \mu \mathrm{A}$ with a resolution of $33 \mathrm{pA}$. All electrodes were electronically connected so that under open-circuit conditions the net array current was zero. Data acquisition was controlled by software installed in a personal computer.

The coating bath used in this study contained $5.4 \mathrm{~g} / \mathrm{L} \mathrm{CrO}_{3}, 0.9$ $\mathrm{g} / \mathrm{L} \mathrm{K}{ }_{3} \mathrm{Fe}(\mathrm{CN})_{6}$, and $0.9 \mathrm{~g} / \mathrm{L} \mathrm{NaF}$, which is close to the composition of an Alodine $1200 \mathrm{~S}$ bath. ${ }^{27}$ This chemistry was used to make all CCCs unless otherwise indicated.
In preparation for conversion coating, electrode arrays were polished to 600 grit using $\mathrm{SiC}$ paper. Arrays were then immersed in dilute nitric acid for $1 \mathrm{~min}$ to obtain a clean surface. The electrode array was then connected to the MMA and immersed in the coating solution for various lengths of time. The current on each electrode was sampled at a rate of $50 \mathrm{~Hz}$. After coating, the array was then rinsed in distilled water and dried with warm flowing air. The electrode array was allowed to dry in air for $24 \mathrm{~h}$ before the anodic polarization measurement.

In breakdown experiments, the entire array was operated as a working electrode in a three-electrode anodic polarization experiment. A built-in potentiostat was used to polarize the array. Measurements were made in a $0.5 \mathrm{M} \mathrm{NaCl}$ solution at a scan rate of 0.2 $\mathrm{mV} / \mathrm{s}$ starting from open circuit potential (OCP). All potentials reported are quoted $v s$. the saturated calomel electrode (SCE). Breakdown (pitting) events were recorded on each electrode during the measurement until all electrodes in the array broke down.

To prevent crevice corrosion, a low-viscosity epoxy (EPO-THIN by Buehler ${ }^{\circledR}$ ) was used to mount the aluminum wire array. After the polarization, the electrode array was examined under an optical microscope. If breakdown occurred at the perimeter area of the electrode, that breakdown potential was discarded to exclude the possibility of crevice corrosion affecting the data sets. It was noted that breakdown in the perimeter area did not necessarily correspond to a low breakdown potential in these electrodes, however.

Raman spectroscopy.-The use of the peak at $859 \mathrm{~cm}^{-1}$ due to $\mathrm{Cr}^{6+}-\mathrm{O}-\mathrm{Cr}^{3+}$ stretch for examining $\mathrm{CCCs}$ has been thoroughly documented. ${ }^{10}$ This peak was measured ex situ to study the evolution of CCCs. Raman spectra of CCCs were collected using a Chromex 2000 spectrometer, with a standard interference band reject filter and EEV 15-11 deep depletion charge-coupled device (CCD). A $785 \mathrm{~nm}$ excitation and $180^{\circ}$ backscattered sampling geometry were employed to obtain the Raman spectra. The instrument was frequency-calibrated with 4-acetamidophenol (Tylenol) and the intensity was calibrated with a glass that has known intensityfrequency curve. The area under $859 \mathrm{~cm}^{-1}$ peak after baseline correction was used to indicate the amount of $\mathrm{Cr}^{6+}$ in CCCs.

\section{Results}

Coating formation.-Current transients during CCC formation exhibit two distinct stages: (i) an initial 30 s period of intense electrochemical activity characterized by large net currents on electrode elements, and (ii) a subsequent stage characterized by electrochemical quiescence in which net currents were very small. The polarity of the net current during the first stage of coating growth varied from electrode to electrode and indicated the dominant reaction on the electrode as well as the progress of coating formation. Some electrodes showed extensive, almost periodic oscillation between anodic and cathodic polarities. Figure 2 shows the current evolution during coating formation on an electrode exhibiting pronounced current oscillations. Other electrodes exhibited more or less persistent anodic or cathodic activity during the initial stage of CCC formation. The current $v s$. time behavior of these electrodes is shown in Fig. 3 and 4, respectively.

Effect of supplemental bath ingredients on coating formation.$\mathrm{NaF}$ additions to the coating bath have a significant effect on the current evolution during coating formation. Figure 5 shows current evolution when $\mathrm{NaF}$ is present or absent. When $\mathrm{NaF}$ is absent, the maximum current observed is smaller than when $\mathrm{NaF}$ is present. Additionally, the current decreases more rapidly when $\mathrm{NaF}$ is absent, suggesting a more rapid cessation of coating growth.

The effect of $\mathrm{K}_{3} \mathrm{Fe}(\mathrm{CN})_{6}$ additions on current evolution is shown in Fig. 6. It appeared that the time required for electrodes to passivate was increased when $\mathrm{K}_{3} \mathrm{Fe}(\mathrm{CN})_{6}$ was absent from the coating bath.

Effect of coating time on CCC breakdown.-Anodic polarization curves were collected separately for each element in the array after 


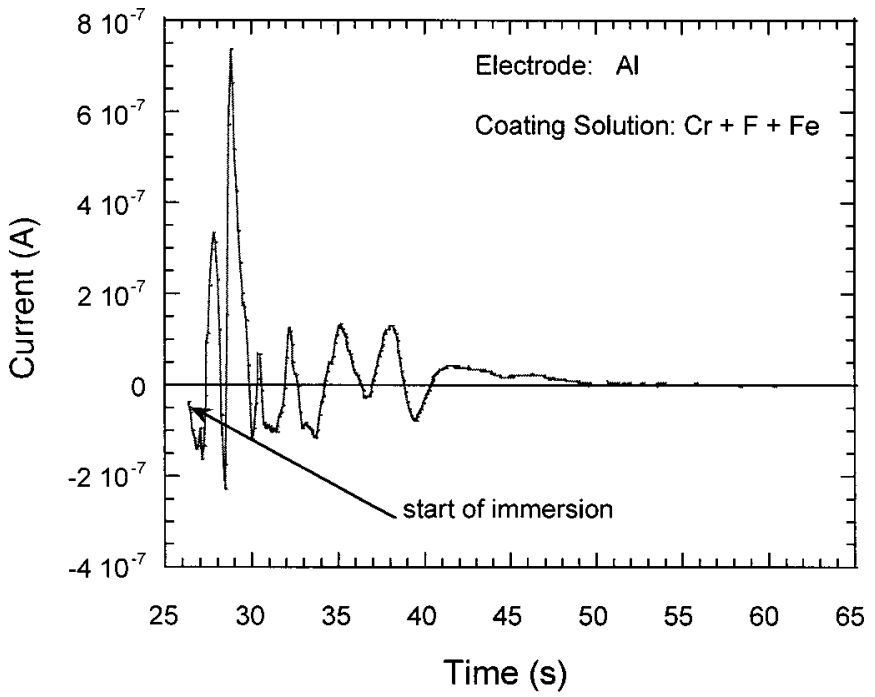

Figure 2. Representative current $v s$. time behavior for an electrode that exhibited distinct current oscillations during early $\mathrm{CCC}$ formation. In the coating solution notation, $\mathrm{Cr}, \mathrm{F}$, and $\mathrm{Fe}$ stand for $\mathrm{CrO}_{3}, \mathrm{NaF}$, and $\mathrm{K}_{3} \mathrm{Fe}(\mathrm{CN})_{6}$, respectively. The same notations are used for the rest of the figures.

the conversion coating was dried in air for $24 \pm 1 \mathrm{~h}$. During potentiodynamic polarization, the CCC breaks down locally and stable pitting develops on the substrate. Pitting is detected as a sharp break in the polarization curve of the electrodes. Metastable pitting was not usually detected. The potential at which this break occurs is termed the "breakdown" potential. Figure 7 shows a typical anodic polarization curve on one electrode element. The breakdown potentials of two electrode arrays totaling more than 40 measurements were collected for each distinctive coating condition.

Each set of breakdown potential data was plotted as cumulative probability vs. breakdown potential. Because breakdown potential data are usually scattered, the cumulative probability plotting approach is a good way to illustrate the distribution in the measurement population. ${ }^{20,21,28}$ Some otherwise indistinguishable trends in the breakdown potentials can be clearly seen in these types of plots.

Coating time has a significant effect on measured breakdown potential distribution (BPD). CCCs are usually formed by 1-3 min of immersion. In Fig. 8, it can be seen that breakdown potentials

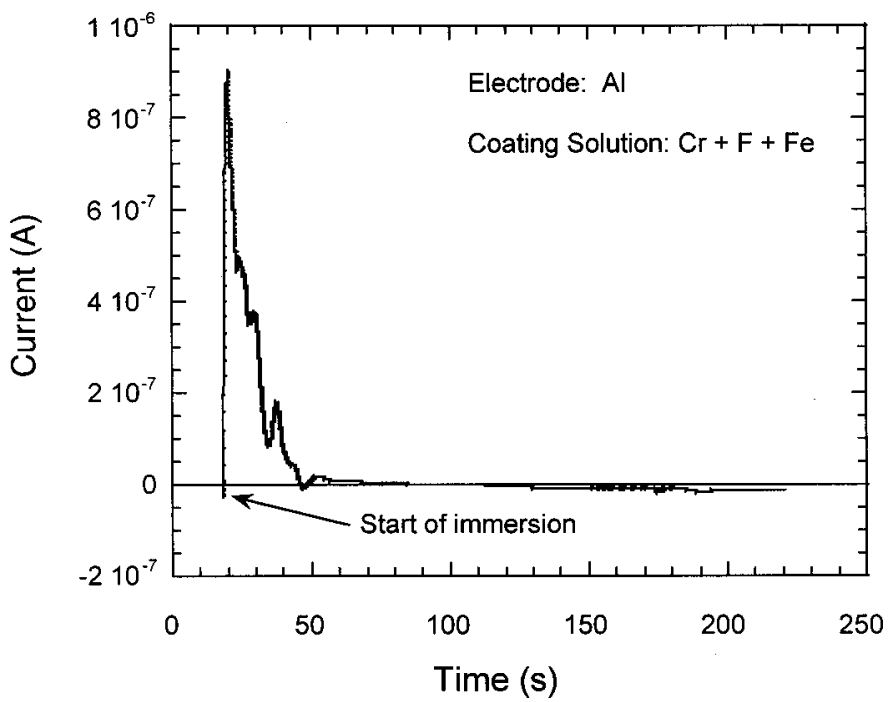

Figure 3. Representative current $v s$. time behavior for electrodes exhibiting persistent anodic behavior during early CCC formation.

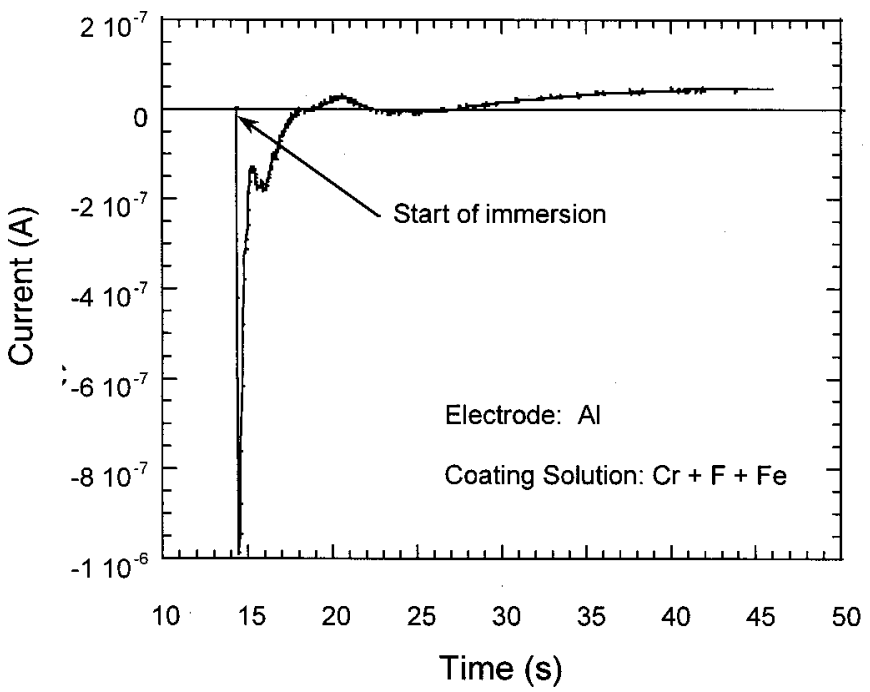

Figure 4. Representative current $v s$. time behavior for an electrode exhibiting persistent cathodic behavior during early CCC formation.

increase with coating time up to $2 \mathrm{~min}$. Increasing coating time from 2 to 5 min does not increase the breakdown potential significantly. Even a few seconds of immersion showed a marked shift in the BPD to more positive potentials. Dramatic increases in breakdown resistance were achieved within the first $30 \mathrm{~s}$ of immersion, where the median breakdown potential increased $0.25 \mathrm{~V}$ from $-0.74 \mathrm{~V}$ for bare $\mathrm{Al}$ to $-0.49 \mathrm{~V}$. By comparison, the median breakdown potential increased by only an additional $0.09 \mathrm{~V}$ when coating time was increased from 30 to $300 \mathrm{~s}$.

Effect of formation current polarity on CCC breakdown.During the first stage of coating formation, two primary reactions occur on each electrode: aluminum oxidation and chromate reduction. When aluminum oxidation is dominant, the electrode acts as a net anode. When chromate reduction is dominant, the electrode acts as a net cathode. Therefore, the difference in polarity of the current on each electrode during coating formation may be associated with a change in coating composition or thickness and thus a change in the resistance to breakdown. The data in Fig. 9 support this idea. In this figure, breakdown potential data from conversion-coated electrodes were segregated according to the net current characteristics observed

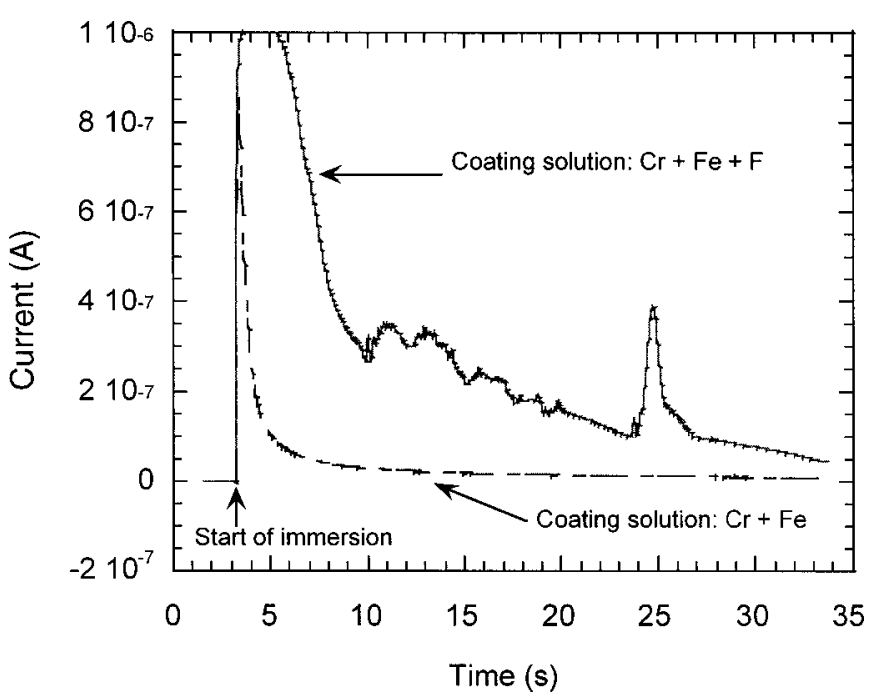

Figure 5. The effect of $\mathrm{F}^{-}$on current evolution on $\mathrm{Al}$ during early $\mathrm{CCC}$ formation. 


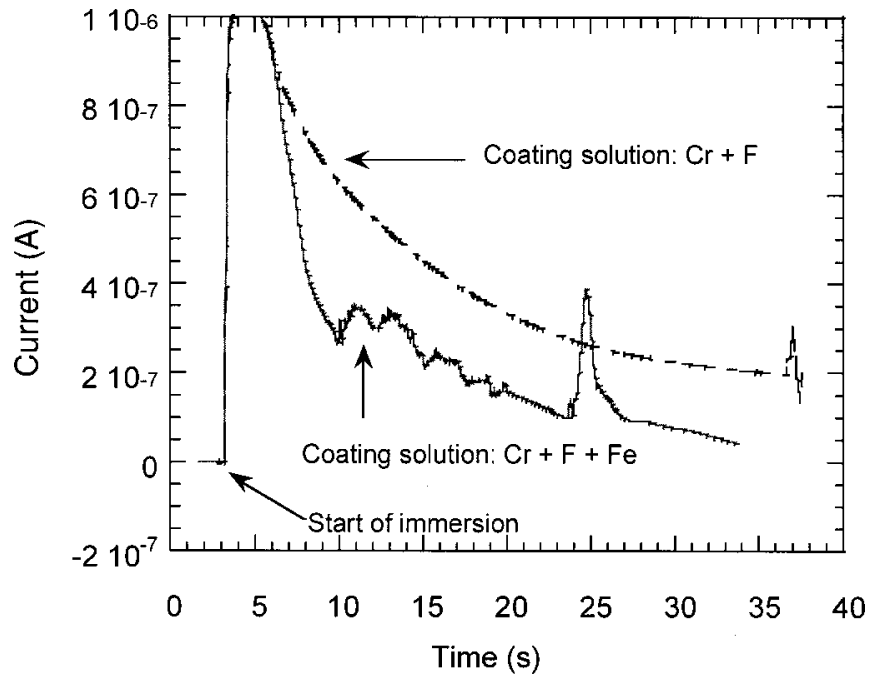

Figure 6. Effect of $\mathrm{Fe}(\mathrm{CN})_{6}^{3-}$ on current evolution on $\mathrm{Al}$ during $\mathrm{CCC}$ formation.

during the first stage of a 3 min immersion in a CCC bath. "Net anodes" exhibited predominantly anodic current during the first $30 \mathrm{~s}$ of coating formation, "net cathodes" exhibited predominantly cathodic current, and "mixed character" electrodes exhibited significant currents of both polarity. Comparison of these BPDs shows that net cathodes are possibly more resistant to breakdown than electrodes of mixed current character, and are much more resistant than electrodes that were net anodes.

Effect of supplemental bath ingredients on CCC breakdown.-Of the three main components of $\mathrm{CCC}$ bath, $\mathrm{NaF}$ has been classified as activator, and $\mathrm{K}_{3} \mathrm{Fe}(\mathrm{CN})_{6}$ as an accelerator. ${ }^{18}$ Figure 10 shows the effect of $\mathrm{NaF}$ and $\mathrm{K}_{3} \mathrm{Fe}(\mathrm{CN})_{6}$ additions on the BPDs for a fixed coating time of $2 \mathrm{~min}$. CCCs formed in a $\mathrm{CrO}_{3}$-only solution increase the median breakdown potential only slightly; approximately $0.01 \mathrm{~V}$ over bare Al. When $\mathrm{NaF}$ is added to the bath the median breakdown potential increases by about $0.23 \mathrm{~V}$ over the $\mathrm{CrO}_{3}$-only median. When $\mathrm{K}_{3} \mathrm{Fe}(\mathrm{CN})_{6}$ is added, the increase is about $0.04 \mathrm{~V}$. These results illustrate the importance of these supplemental bath ingredients on CCC formation. Without these additions, it is likely that coatings with useful levels of corrosion protection do not form.

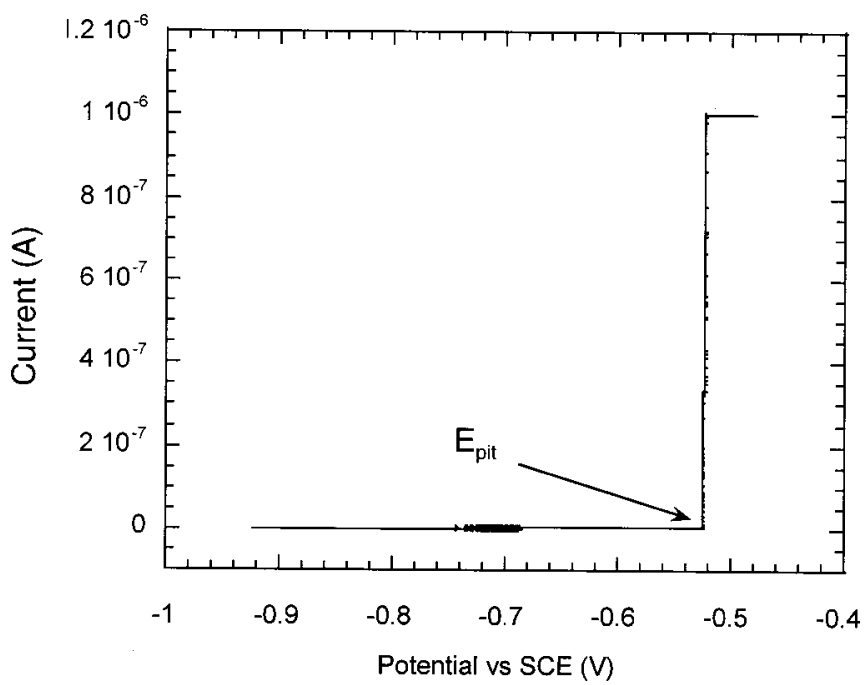

Figure 7. A typical anodic polarization curve on an $\mathrm{Al}$ wire electrode coated with $\mathrm{CCC}$ in $0.5 \mathrm{M} \mathrm{NaCl}$ solution.

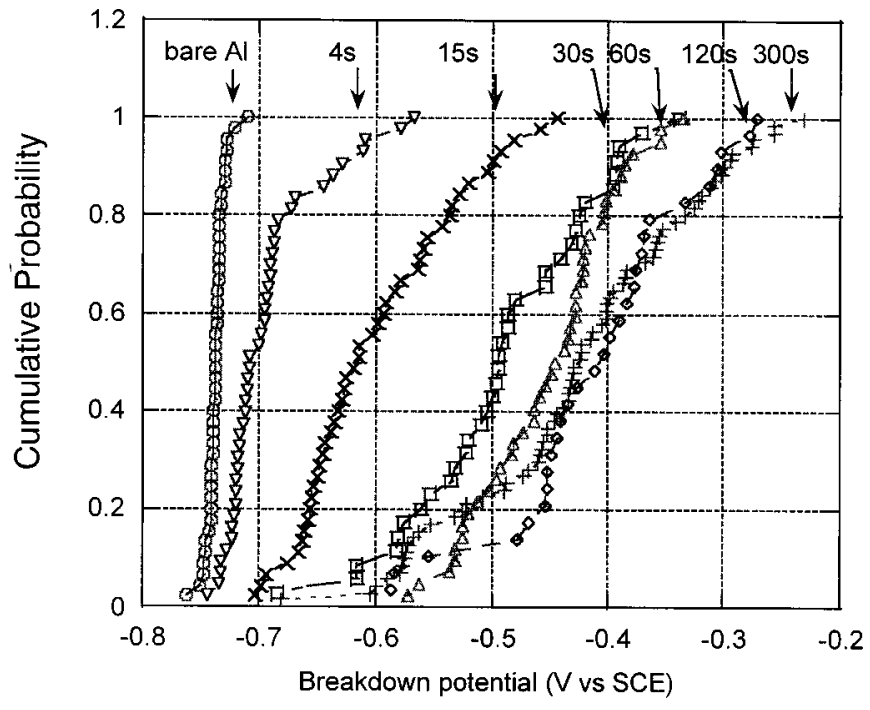

Figure 8. Effect of coating time on CCC breakdown potential distribution. Coating solution: $\mathrm{CrO}_{3}+\mathrm{NaF}+\mathrm{K}_{3} \mathrm{Fe}(\mathrm{CN})_{6}$.

Both $\mathrm{NaF}$ as an activator, and $\mathrm{K}_{3} \mathrm{Fe}(\mathrm{CN})_{6}$ as a redox accelerator, might be expected to exert their greatest effect on corrosion protection during the first stage of CCC formation where apparent electrochemical activity is greatest. To examine this possibility, CCCs were formed in the presence and absence of $\mathrm{NaF}$ and $\mathrm{K}_{3} \mathrm{Fe}(\mathrm{CN})_{6}$ for 30 $\mathrm{s}$, where all coating growth occurs during the electrochemically active stage. Complementary coating experiments were performed where the coating time was fixed at $2 \mathrm{~min}$. In this case, most of the coating growth is expected to occur during the electrochemically quiescent stage of growth. BPDs were measured on coatings formed in these experiments and are shown in Fig. 11 and 12.

In these figures, the BPD for bare $\mathrm{Al}$ and the $30 \mathrm{~s}$ and $2 \mathrm{~min}$ coatings containing $\mathrm{CrO}_{3}, \mathrm{NaF}$, and $\mathrm{K}_{3} \mathrm{Fe}(\mathrm{CN})_{6}$ are the same data sets. In Fig. 11, the BPDs are identical for coatings formed in the absence of $\mathrm{NaF}$, suggesting that the action of $\mathrm{K}_{3} \mathrm{Fe}(\mathrm{CN})_{6}$ to improve corrosion protection is complete in $30 \mathrm{~s}$. This is not the case for $\mathrm{NaF}$. Figure 12 shows BPDs for CCCs formed in the absence of $\mathrm{K}_{3} \mathrm{Fe}(\mathrm{CN})_{6}$. The $2 \mathrm{~min} \mathrm{BPD}$ is shifted considerably to more positive potentials, suggesting that $\mathrm{NaF}$ acts over the entire coating for-

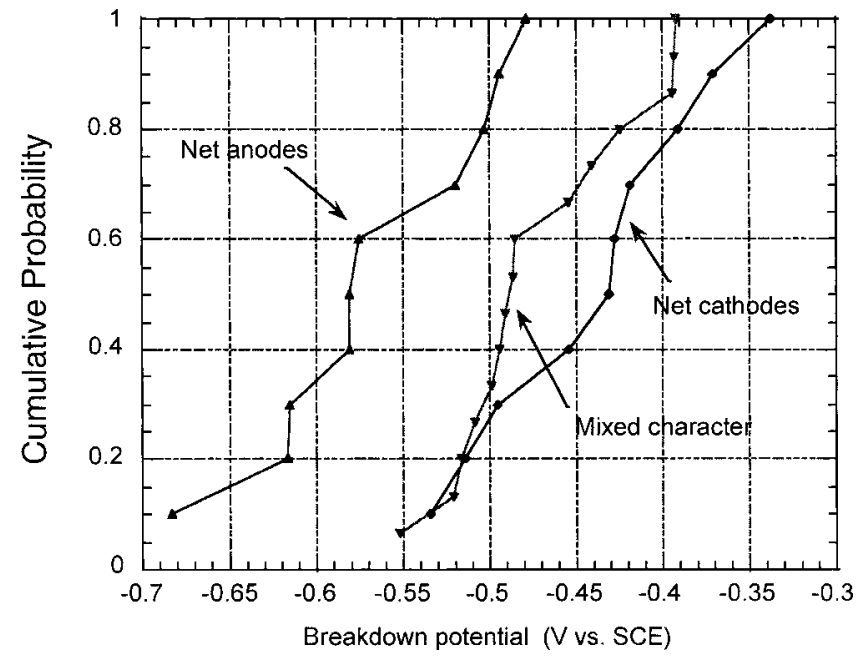

Figure 9. Effect of polarity during coating formation on coating breakdown potential distribution. Coating solution: $\mathrm{CrO}_{3}+\mathrm{NaF}+\mathrm{K}_{3} \mathrm{Fe}(\mathrm{CN})_{6}$. Coating time: $3 \mathrm{~min}$. 


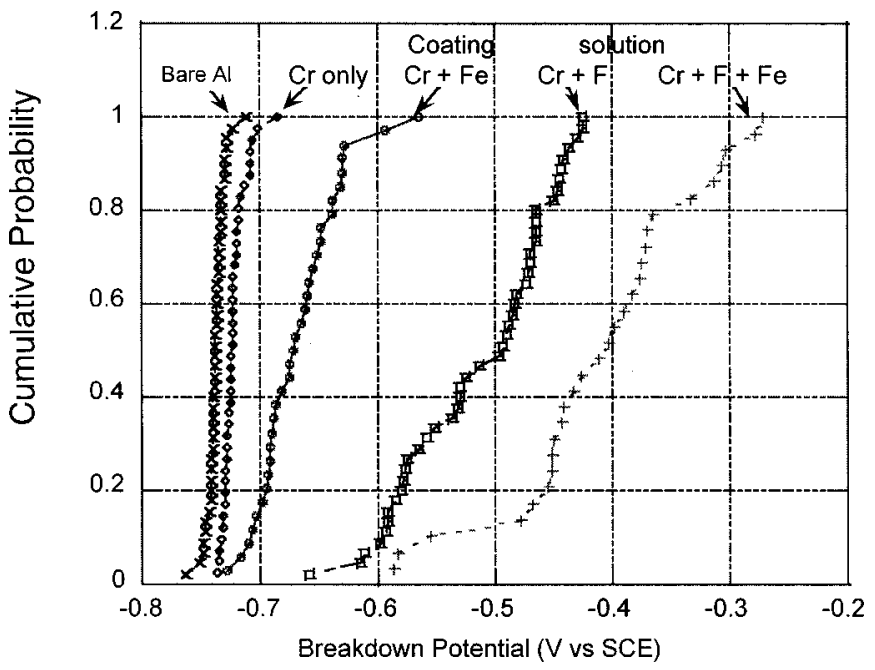

Figure 10. Relative contributions of coating bath components to coating breakdown potential. Coating time: $2 \mathrm{~min}$.

mation period to increase resistance to breakdown. $\mathrm{NaF}$ and $\mathrm{K}_{3} \mathrm{Fe}(\mathrm{CN})_{6}$ clearly work together to improve resistance to breakdown as BPDs for coatings formed in the "full" chemistry exhibit the most noble BPDs by far.

Alternate accelerators.-To explore the role of the accelerator in $\mathrm{CCC}$ formation further, $\mathrm{K}_{3} \mathrm{Fe}(\mathrm{CN})_{6}$ was replaced with another possible accelerator, $\mathrm{Fe}\left(\mathrm{NO}_{3}\right)_{3}$. In this case, the $\mathrm{Fe}^{3+} / \mathrm{Fe}^{2+}$ couple was intended to serve as the redox mediator. In this coating bath the molar concentration of $\mathrm{Fe}^{3+}$ was made identical to that of $\mathrm{Fe}(\mathrm{CN})_{6}^{3-}$, and the BPDs of the coatings formed in these two chemistries were compared. The results are shown in Fig. 13. The coatings formed in $\mathrm{Fe}\left(\mathrm{NO}_{3}\right)_{3}$-containing bath have much lower breakdown potentials than those formed in $\mathrm{K}_{3} \mathrm{Fe}(\mathrm{CN})_{6}$-containing bath and show only very limited improvement over bare Al. Compared with coatings formed in $\mathrm{CrO}_{3}+\mathrm{NaF}$ bath, $\mathrm{Fe}\left(\mathrm{NO}_{3}\right)_{3}$ shows adverse effect on coating breakdown potentials.

Effect of minor bath ingredients on CCC breakdown.--It is of interest to know how the coatings formed in simulated Alodine bath perform compared with those formed in actual Alodine 1200S bath. By comparing the BPD from the simulated Alodine coatings to coat-

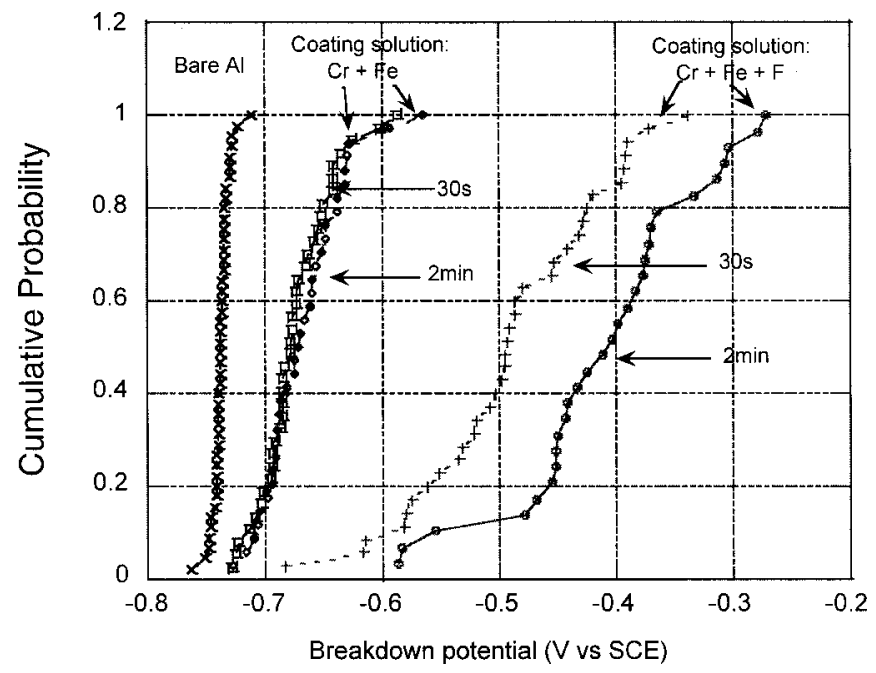

Figure 11. Effect of $\mathrm{K}_{3} \mathrm{Fe}(\mathrm{CN})_{6}$ on coating breakdown potential distribution.

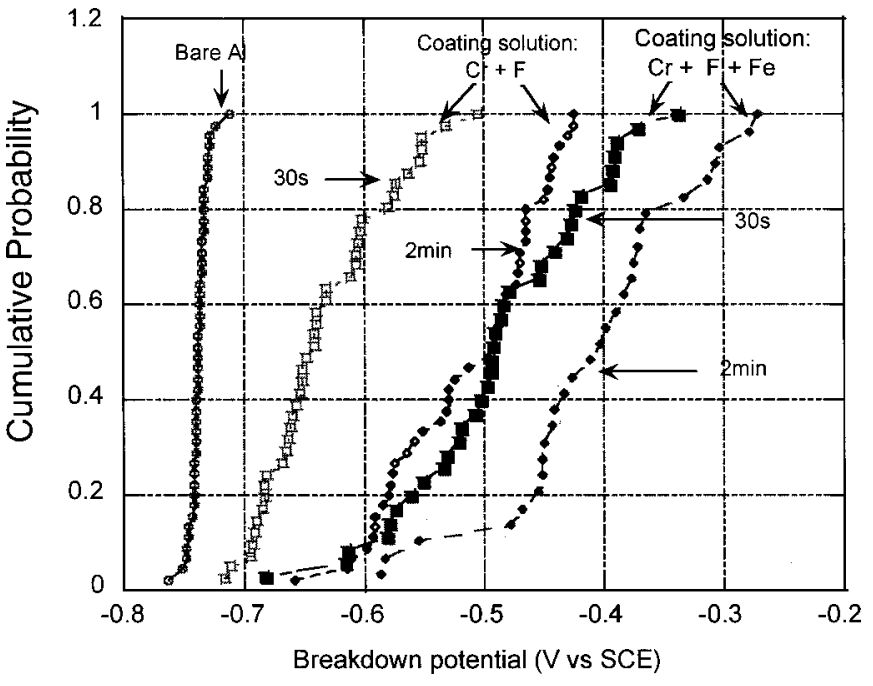

Figure 12. Effect of $\mathrm{NaF}$ on coating breakdown potential.

ings made from commercial product we were able to assess the influence of other minor ingredients, such as $\mathrm{KBF}_{4}$ and $\mathrm{K}_{2} \mathrm{ZrF}_{6} \cdot{ }^{27}$ Figure 14 shows the BPD of coatings formed in simulated and actual Alodine 1200S solution. The data show that the coatings formed in simulated Alodine are in fact better than coatings formed in actual Alodine 1200S, at least in terms of breakdown potentials. It has also been observed that CCCs formed in simulated chemistry perform better than those formed with Alodine $1200 \mathrm{~S}$ in salt spray tests. ${ }^{20}$ In these experiments, the minor ingredients such as $\mathrm{KBF}_{4}$ and $\mathrm{K}_{2} \mathrm{ZrF}_{6}$ in Alodine $1200 \mathrm{~S}$ do not appear to have a significant influence on the breakdown resistance of CCCs.

$\mathrm{Cr}^{6+}$ concentration in CCCs determined by Raman spectroscopy.-Figure 15 shows Raman spectra of conversion coatings on pure $\mathrm{Al}$ in the $859 \mathrm{~cm}^{-1}$ region. Figure 16 shows the peak area integral, which is taken as a measure of the scattering intensity of the $\mathrm{Cr}^{6+}-\mathrm{O}-\mathrm{Cr}^{3+}$ stretch in the $\mathrm{CCC}$ structure. A representative net current transient measured during CCC formation is superimposed on the plot. Data for CCCs on pure Al and 2024-T3 substrates are reported. Each data point in Fig. 16 is the average of four measurements on the same sample at different locations. As coating time increases, the intensity of the scattering band increases. This finding

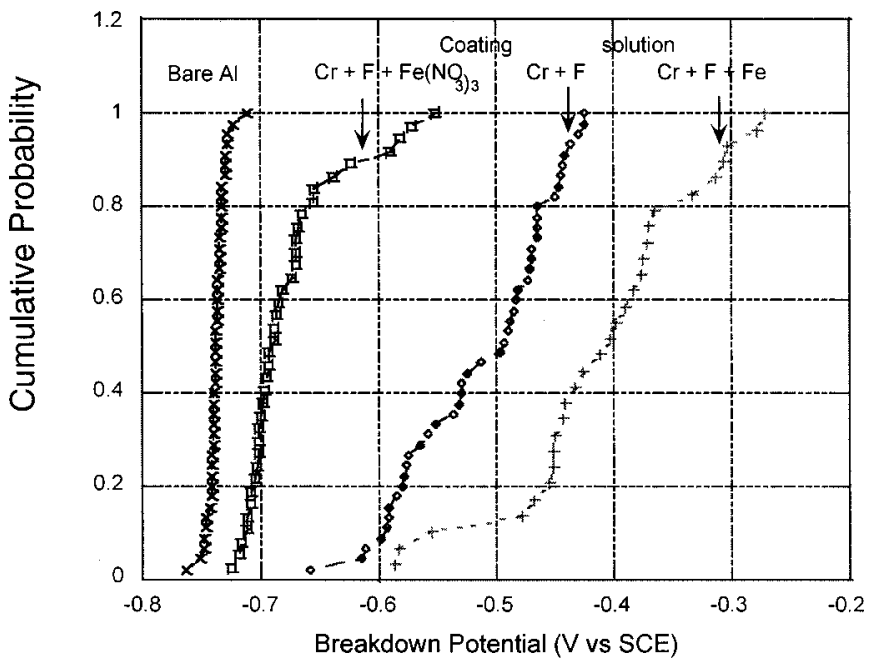

Figure 13. Effect of $\mathrm{Fe}\left(\mathrm{NO}_{3}\right)_{3}$ on coating breakdown potential distribution. Coating time: $2 \mathrm{~min}$. 


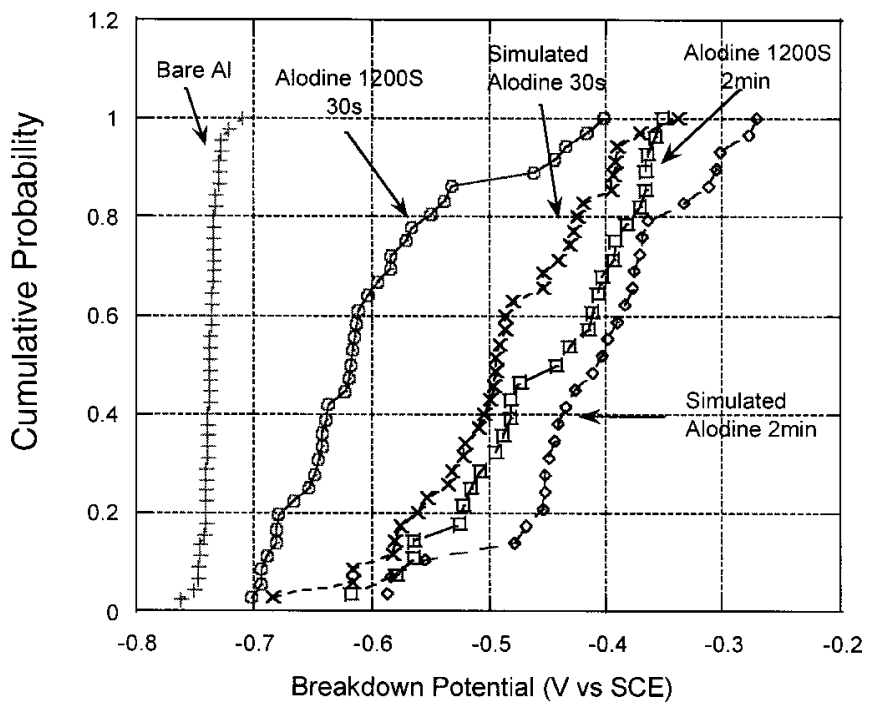

Figure 14. Comparison of breakdown behavior of CCCs formed in simulated Alodine and on Alodine 1200S solution prepared according to manufacturer's specifications.

is generally consistent with $\mathrm{X}$-ray absorption near-edge spectroscopy (XANES) results, which also show that the total $\mathrm{Cr}$ and $\mathrm{Cr}^{6+}$ concentration in the CCC increases over this time frame. ${ }^{21,29}$ The data in Fig. 16 indicate significant CCC evolution (growth and/or chemistry change) in the absence of measurable electrochemical current, suggesting the possibility that a major episode of CCC formation may not be electrochemical in nature.

\section{Discussion}

CCC formation process on Al-- $\mathrm{CCC}$ formation on $\mathrm{Al}$ is commonly described as an electrochemical process involving oxidation of $\mathrm{Al}$ and reduction of $\mathrm{Cr}^{6+}$ to $\mathrm{Cr}^{3+3,11,30}$

$$
\begin{gathered}
\mathrm{Al} \rightarrow \mathrm{Al}^{3+}+3 \mathrm{e}^{-} \\
\mathrm{Al}+2 \mathrm{H}_{2} \mathrm{O} \rightarrow \mathrm{AlOOH}+3 \mathrm{H}^{+}+3 \mathrm{e}^{-} \\
\mathrm{Cr}_{2} \mathrm{O}_{7}^{2-}+8 \mathrm{H}^{+}+6 \mathrm{e}^{-} \rightarrow 2 \mathrm{Cr}(\mathrm{OH})_{3} \downarrow+\mathrm{H}_{2} \mathrm{O}
\end{gathered}
$$

Coating growth occurs when $\mathrm{Cr}^{3+}$ hydrolyzes, condenses, and polymerizes on the aluminum surface to form an amorphous, hydrous layer. ${ }^{10}$ While the trivalent chromium hydroxide forms on the elec-

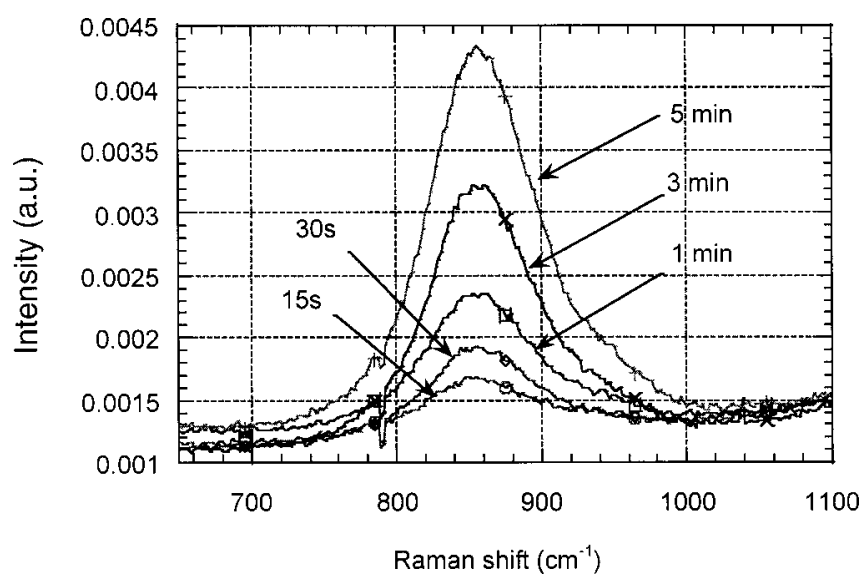

Figure 15. The intensity of the $860 \mathrm{~cm}^{-1}$ band in Raman spectra increases with coating time, indicating the buildup of $\mathrm{Cr}^{6+}$ in CCCs. Coating solution $\mathrm{CrO}_{3}+\mathrm{NaF}+\mathrm{K}_{3} \mathrm{Fe}(\mathrm{CN})_{6}$

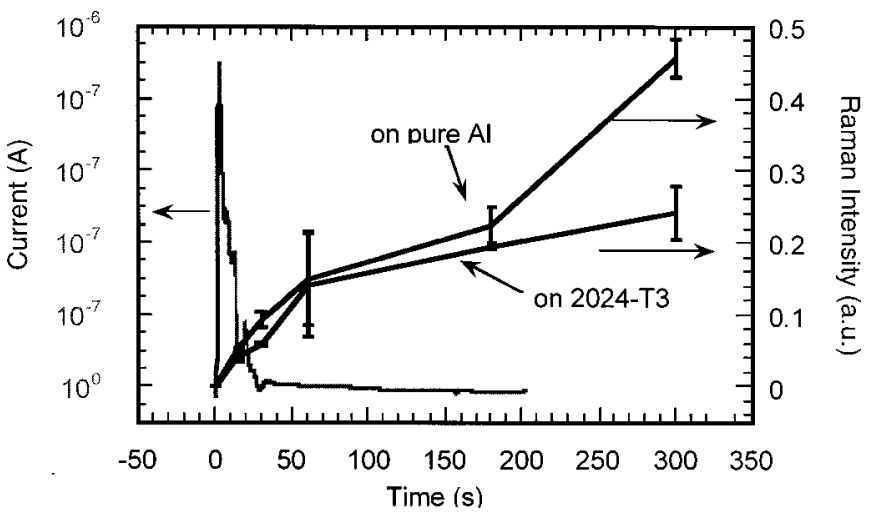

Figure 16. Normalized intensity of the $859 \mathrm{~cm}^{-1} \mathrm{Cr}^{3+}-\mathrm{O}-\mathrm{Cr}^{6+}$ scattering band as a function of coating time. A representative current $v s$. time trace is shown for comparison.

trode surface from the coating bath, chromates are adsorbed onto it. ${ }^{10}$ Chromates are known to adsorb strongly onto many oxides and hydroxides, ${ }^{31-33}$ and adsorption of chromate on the $\mathrm{Cr}^{3+}$ hydroxide is likely to be favored in the acidic environment of coating bath because the adsorption reaction consumes protons. ${ }^{10}$ In service environments which are less acidic, desorption is favored, leading to self-healing characteristics. . $^{11,17,29,34,35}$

Figure 16 raises the possibility that a significant component of CCC growth can be chemical in nature. Specifically, the figure shows that intense net currents are measured on the array for only about $30 \mathrm{~s}$ during coating formation. However, the $859 \mathrm{~cm}^{-1}$ Raman band intensifies over the entire $300 \mathrm{~s}$ coating formation interval. Arguably, this result is equivocal with respect to nonelectrochemical film growth in later stages of the coating process, because the current measured on an electrode is a net current. In other words, low or no net current does not necessarily mean no or low electrochemical activity on an electrode. Nonetheless, the result of CCC formation is electrode passivation. Figure 16 suggests that electrochemical passivation may be largely complete early in the coating process. Provided that sufficient $\mathrm{Cr}^{3+}$ is produced by electrochemical reduction and retained in the electrolyte near the metal surface in the early stages of the coating process, continued CCC growth by $\mathrm{Cr}^{3+}$ hydrolysis, polymerization, and condensation, combined with adsorption of chromate, ${ }^{10}$ would account for continued evolution of the $\mathrm{CCC}$ in the latter stages of the coating process, even though the $\mathrm{Al}$ surface is electrochemically passive. In any case, these results enable CCC formation to be divided into two distinct stages: one characterized by intense measurable electrochemical activity, and a second that occurs under comparatively quiescent conditions.

Lateral coating heterogeneity.-The results in Fig. 9 shows that net cathodes are more resistant to breakdown than net anodes. Further characterization of the coatings formed on net cathodes and net anodes is necessary to understand why they behave differently. However, it is expected that net cathodes support $\mathrm{Cr}^{6+}$ reduction at higher rates and are therefore richer in Cr hydroxide than net anodes. Cr hydroxide enrichment might reasonably be expected to translate into increased corrosion resistance. If this is so, CCC formation on engineering alloys probably occurs unevenly because anodic and cathodic activity is localized by microstructural heterogeneity. This may result in regions of differing corrosion resistance. In microtomed cross sections on Al alloys, Brown et al. have found Cr-rich deposits on isolated regions of Fe surface enrichment after conversion coating in $\mathrm{CrO}_{3}-\mathrm{NaF}$ solutions. ${ }^{36}$

Effects of coating bath chemistry on coating formation and breakdown behavior.-The functions of $\mathrm{NaF}$ and $\mathrm{K}_{3} \mathrm{Fe}(\mathrm{CN})_{6}$ in coating formation have been studied by several groups and theories have been put forward describing their role in CCC formation. It has 


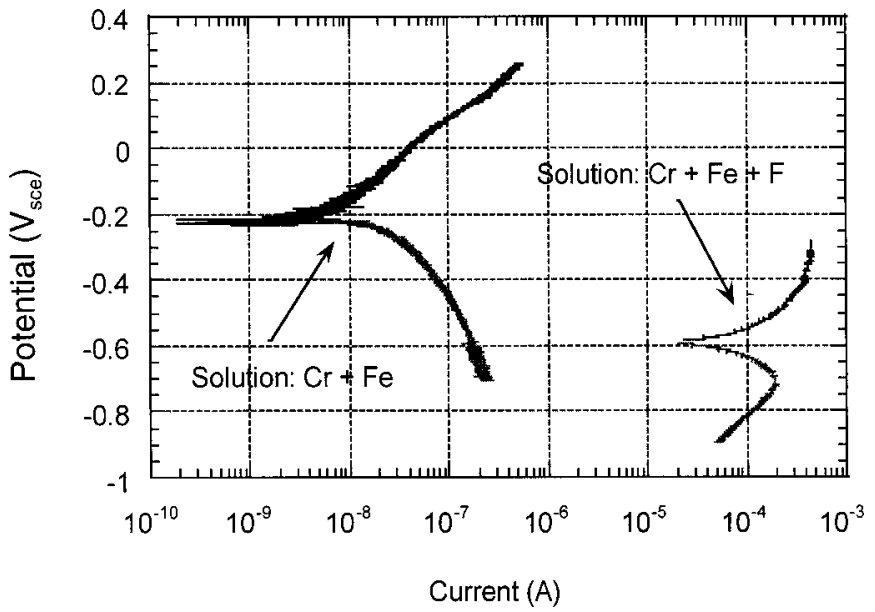

Figure 17. Polarization response of pure $\mathrm{Al}$ in simulated Alodine solution with and without $\mathrm{F}^{-}$additions.

been observed that without $\mathrm{F}^{-}$coating formation is very slow. It has been suggested that $\mathrm{F}^{-}$dissolves the oxide film initially present on $\mathrm{Al}$ surface and activates the surface for chromate reduction. ${ }^{3,8}$ The reaction has been proposed to occur as

$$
\mathrm{Al}_{2} \mathrm{O}_{3}+6 \mathrm{HF} \rightarrow 2 \mathrm{AlF}_{3}+3 \mathrm{H}_{2} \mathrm{O}
$$

During coating growth, $\mathrm{F}^{-}$may also delay film formation in a manner that sustains electrochemical reactions. Without $\mathrm{F}^{-}$, the surface rapidly passivates, and film growth stops having only formed a very thin film with limited corrosion protection. The results from this experiment support these arguments. As shown in Fig. 5, when $\mathrm{F}^{-}$is absent, the peak current during coating formation is generally lower and the current drops very sharply in the first several seconds of coating formation. The smaller area under the curve measured in the absence of $\mathrm{F}^{-}$indicates that the extent of the coating formation reaction is reduced compared to when $\mathrm{F}^{-}$is present. Once formed, this thin layer prevents further contact between coating solution and Al surface and coating growth slows or ceases. Apparently, the thin coating that is formed is not very protective in $\mathrm{Cl}^{-}$solutions.

The role of $\mathrm{F}^{-}$in promoting electrochemical reactions can be seen very clearly in potentiodynamic polarization experiments. As shown in Fig. 17, the corrosion rate at the OCP when $\mathrm{F}^{-}$is present is three orders of magnitude greater than that when $\mathrm{F}^{-}$is absent. A feature in the cathodic polarization curve in the presence of $\mathrm{F}^{-}$is that the current decreases with increased cathodic overpotential, suggesting coating formation on the Al surface. This was confirmed by scanning electron microscopy (SEM) observations. Figure 18 shows the surface morphology of pure Al after immersion in different coating bath chemistries. Without $\mathrm{F}^{-}$in the coating bath, there is little change on the $\mathrm{Al}$ surface. With all three ingredients, the familiar mud-cracking pattern of CCCs was observed on Al.

It has been reported that when ferricyanide is added to the coating bath, the coating weight, coating thickness, formation rate, and coating corrosion resistance are increased. ${ }^{2,8,9,18,37}$ Comparison between the BPDs with and without $\mathrm{Fe}(\mathrm{CN})_{6}^{3-}$ indicates that the coating corrosion resistance is indeed increased when $\mathrm{Fe}(\mathrm{CN})_{6}^{3-}$ is added to the coating bath. The function of ferricyanide has been examined by Xia and McCreery, ${ }^{19}$ who suggest that the sluggish oxidation of $\mathrm{Al}$ by chromate is greatly increased because $\mathrm{Fe}(\mathrm{CN})_{6}^{3-}$ rapidly oxidizes $\mathrm{Al}$. The reduction product of $\mathrm{Fe}(\mathrm{CN})_{6}^{3-}$, $\mathrm{Fe}(\mathrm{CN})_{6}^{4-}$, reduces chromate to complete the mediation cycle.

The results of BPD measurement with and without $\mathrm{Fe}(\mathrm{CN})_{6}^{3-}$ in the coating bath are consistent with ferri/ferrocyanide mediation. According to this mechanism, $\mathrm{Fe}(\mathrm{CN}){ }_{6}^{3-}$ mainly affects electro-

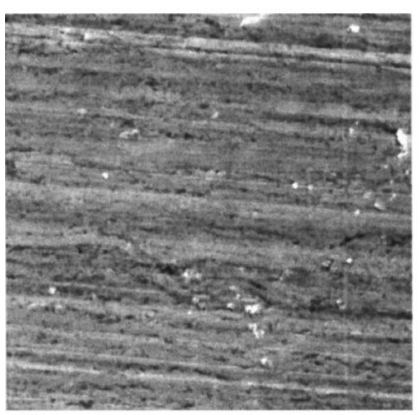

a

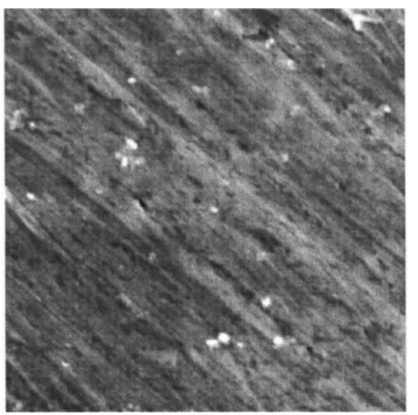

b

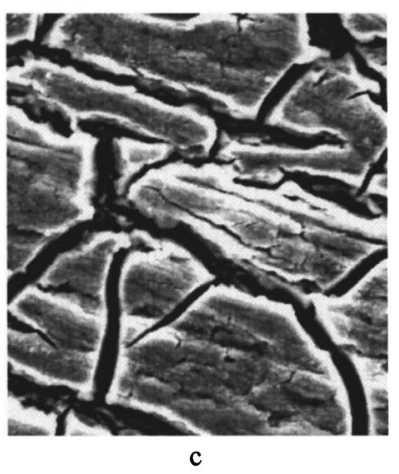

$5 \mu \mathrm{m}$

Figure 18. Morphology of coatings formed in different chemistries: (a) bare $\mathrm{Al}$, (b) in $\mathrm{Cr}+\mathrm{Fe}$, and (c) in $\mathrm{Cr}+\mathrm{Fe}+\mathrm{F}$. Coating time: 2 min.

chemical reactions, and it might be expected that its effect on coating BPD would be more pronounced for coatings formed in $30 \mathrm{~s}$ than coatings formed in $2 \mathrm{~min}$, since electrochemical activity mainly occurs in the first $30 \mathrm{~s}$. Results in Fig. 12 indicate that the difference in the median breakdown potentials due to the presence or absence of $\mathrm{Fe}(\mathrm{CN})_{6}^{3-}$ for $30 \mathrm{~s}$ coatings is about $0.07 \mathrm{~V}$ larger than that between 2 min coatings.

$\mathrm{Xia}$ further suggests that any redox system with a redox potential between that of $\mathrm{Cr}^{6+} / \mathrm{Cr}^{3+}$ and $\mathrm{Al}^{0} / \mathrm{Al}^{3+}$ and fast kinetics with those two systems can act as mediator. Their suggested list of possible mediators includes $\mathrm{Fe}^{3+} / \mathrm{Fe}^{2+}$. The results from this study suggest that the $\mathrm{Fe}^{3+} / \mathrm{Fe}^{2+}$ system does not improve the corrosion resistance of CCC. On the contrary, it seems that the addition of $\mathrm{Fe}^{3+}$ has detrimental effect on coating performance, which may be due to precipitation of $\mathrm{Fe}(\mathrm{OH})_{2}$ in locally neutral or alkaline conditions. This indicates that an additional requirement for a redox mediator is that both states of the mediator must be highly soluble. This is true for $\mathrm{Fe}(\mathrm{CN})_{6}^{3-} / \mathrm{Fe}(\mathrm{CN})_{6}^{4-}$ but not true for $\mathrm{Fe}^{3+} / \mathrm{Fe}^{2+}$, because the solubility of $\mathrm{Fe}^{2+}$ is low under the conditions that exist near the substrate surface.

From the results shown in Fig. 10-12 and the discussion concerning the effects of $\mathrm{NaF}$ and $\mathrm{K}_{3} \mathrm{Fe}(\mathrm{CN})_{6}$ on $\mathrm{CCC}$ formation, it is concluded that to form a corrosion-resistant conversion coating, the addition of appropriate supplemental ingredients to the coating bath chemistry are as important as the primary film-forming agent itself. In the case of CCCs, film-forming agent, $\mathrm{CrO}_{3}$, is necessary to form $\mathrm{CCC}$, but without the addition of $\mathrm{F}^{-}$and $\mathrm{Fe}(\mathrm{CN})_{6}^{3-}$ (or other chemicals in different CCC processes), a corrosion-resistant coating will not form. This idea might be important in developing chromate-free coating systems.

Certain types of cerium conversion coatings are examples of this idea already in practice. Soluble $\mathrm{Ce}$ is known to form protective coatings on $\mathrm{Al}$ alloys. ${ }^{38-42}$ However, the formation of films with latent corrosion protection requires tens to hundreds of hours of 


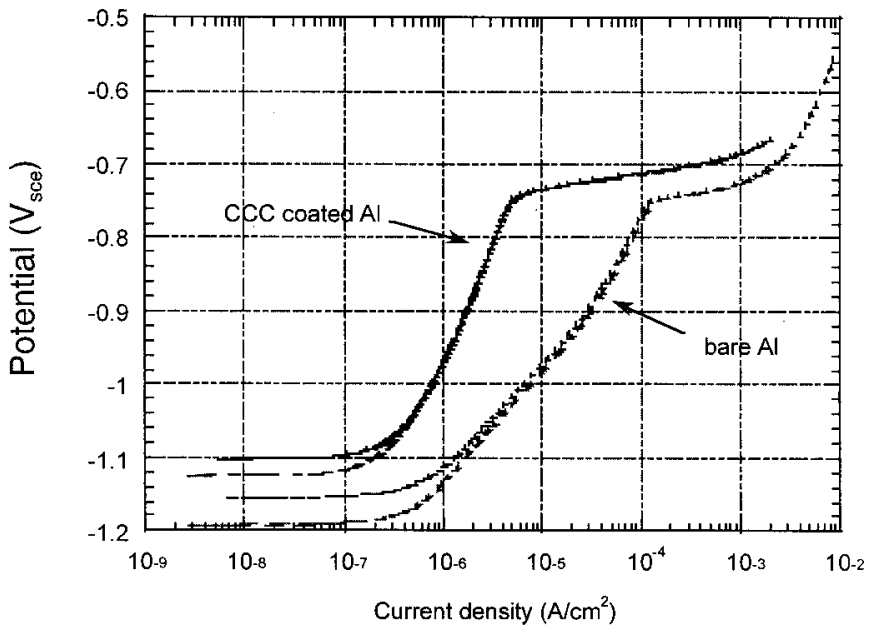

Figure 19. Anodic polarization curves on $1 \mathrm{~cm}^{2} \mathrm{Al}$ samples in $0.5 \mathrm{M} \mathrm{NaCl}$.

exposure to $\mathrm{Ce}$ solutions. Chemical acceleration with $\mathrm{H}_{2} \mathrm{O}_{2}$ additions is extremely effective in reducing coating time. Corrosionresistant $\mathrm{Ce}$ coatings can be formed in a matter of minutes by immersion in $\mathrm{H}_{2} \mathrm{O}_{2}$-modified $\mathrm{Ce}$ coating baths. ${ }^{37}$ Although the chemistry of $\mathrm{Ce}$ conversion coating formation is very different from that of CCCs, it seems that chemical "acceleration" and "activation" might be quite useful as general concepts in conversion coating development.

CCC breakdown, small area electrodes, and anodic inhibition by CCCs.-Pitting potentials (or breakdown potentials) are naturally dispersed. Increasingly, pitting and breakdown potentials are being represented with distribution plots. ${ }^{20,21,28}$ In order to construct such a plot, many tests are necessary to accurately describe the distribution. The MMA is useful in this regard because it functions essentially as a multiplexer, allowing many polarization curves to be collected simultaneously.

Coating breakdown and pitting are dominated by surface defects. These defects may be in the substrate or in the coating, but in any given sample, they exist with some characteristic areal density. Assuming a characteristic areal defect density among similarly prepared electrodes, BPDs are expected to shift to more positive potentials for decreasing electrode area as the likelihood of having a defect that initiates breakdown at a low potential decreases. ${ }^{43,44}$ Essentially, the chances of breakdown at low potentials are greater for large area electrodes than for small area electrodes. The BPDs shown in this paper are believed to capture the breakdown behavior of large area electrodes measured in polarization experiments at the "foot" of the distributions, which all tend to converge (e.g., Fig. 8). To explore this idea, replicate anodic polarization curves were measured for bare $\mathrm{Al}$ and $\mathrm{Al}$ coated with a 2 min CCC. Anodic polarization curves were collected in $0.5 \mathrm{M} \mathrm{NaCl}$ and are shown in Fig. 19. The breakdown potential for $\mathrm{Al}$ is about $-0.75 \mathrm{~V}$ and that for the CCC sample is $-0.74 \mathrm{~V}$. These values agree well with low end of the BPDs in Fig. 8. The breakdown potentials are also within 10 $\mathrm{mV}$ of one another. It is interesting to speculate on whether anodic inhibition has been unfairly overlooked as a contribution to CCC corrosion protection due to the use of large area electrodes in polarization testing.

Evaluation of BPDs in the manner described here to understand corrosion protection by CCCs may be more closely related to evaluation methods like EIS, ${ }^{22}$ or visual examination of samples subject to cabinet exposure testing. ${ }^{45}$ In these evaluations, results reflect the contributions of the entire surface and not just the first breakdown event.

Another important aspect of breakdown potential testing is environmental aggressiveness. Chloride ion concentration may be an important factor in determining whether evidence of anodic inhibition is detected or not. One may conclude that CCCs do not inhibit anodic reactions on the basis of the breakdown potentials shown in Fig. 19, which were obtained in $0.5 \mathrm{M} \mathrm{NaCl}$ solution. However, anodic inhibition by CCCs on bulk samples is supported in results reported by Ilevbare, where the experiments were carried out in 0.1 $\mathrm{M} \mathrm{Na}_{2} \mathrm{SO}_{4}$ plus $0.005 \mathrm{M} \mathrm{NaCl}$ solutions. ${ }^{20,21}$ These findings illustrate the need to consider environmental aggressiveness when interpreting evidence for or against anodic inhibition by CCCs.

\section{Conclusion}

The main findings of this study are summarized as follows

1. In electrochemical measurements, CCC formation occurs in two stages. The first stage occurs in the first $30 \mathrm{~s}$ of CCC formation and is characterized by measurable electrochemical activity. The second stage occurs over the remainder of the coating formation period and is characterized by little measurable electrochemical activity. Coating evolution continues through both of these stages as indicated by increases in the $859 \mathrm{~cm}^{-1}$ Raman scattering band due to $\mathrm{Cr}^{3+}-\mathrm{O}-\mathrm{Cr}^{6+}$ bonding in the CCC.

2. The resistance to breakdown of an electrode in a conversioncoated array is related to the polarity of the current during the first stage of coating formation. Resistance to breakdown decreases in the order

$$
\text { Net cathodes } \sim \text { Mixed polarity }>\text { Net anodes }
$$

3. These results confirm earlier findings that CCCs inhibit anodic reactions. ${ }^{20,21}$ Increasing coating time increases anodic inhibition as indicated by increasing BPDs. Most of the improvement in inhibition occurs in the first $30 \mathrm{~s}$ of coating time.

4. $\mathrm{NaF}$ and $\mathrm{K}_{3} \mathrm{Fe}(\mathrm{CN})_{6}$ both have significant positive effects on $\mathrm{CCC}$ breakdown resistance. $\mathrm{NaF}$ appears to have the larger effect of the two ingredients. Together, these ingredients vastly improve the latent corrosion protection properties of CCCs.

The Ohio State University assisted in meeting the publication costs of this article.

\section{References}

1. J. A. Treverton and N. C. Davis, Met. Technol. (London), 1977, 480 (Oct).

2. J. A. Treverton and N. C. Davis, Surf. Interface Anal., 3, 194 (1981).

3. H. A. Katzman, G. M. Malouf, R. Bauer, and G. W. Stupian, Appl. Surf. Sci., 2, 416 (1979).

4. K. Asami, M. Oki, G. E. Thompson, G. C. Wood, and V. Ashworth, Electrochim. Acta, 32, 337 (1987).

5. F. W. Lytle, R. B. Greegor, G. L. Bibbins, K. Y. Blohowiak, R. E. Smith, and G. D. Tuss, Corros. Sci., 37, 349 (1995).

6. Z. Yu, H. Ni, G. Zhang, and Y. Wang, Appl. Surf. Sci., 62, 217 (1992).

7. H. E. Townsend and R. G. Hart, J. Electrochem. Soc., 131, 1345 (1984).

8. P. L. Hagans and C. M. Haas, Surf. Interface Anal., 21, 65 (1994).

9. A. E. Hughes, R. J. Taylor, and B. R. W. Hinton, Surf. Interface Anal., 25, 223 (1997).

10. L. Xia and R. McCreery, J. Electrochem. Soc., 145, 3083 (1998).

11. M. W. Kendig, A. J. Davenport, and H. S. Isaacs, Corros. Sci., 34, 41 (1993).

12. T. Biestek and J. Weber, Electrolytic and Chemical Conversion Coatings, translated from the Polish by A. Kozlowski, Portcullis Press, Ltd., Redhill, Poland (1976).

13. W. E. Pocock, Met. Finish., 52(12), 48 (1954).

14. N. Sato, Corrosion (Houston), 45, 354 (1989).

15. N. Sato, Corros. Sci., 31, 1 (1990).

16. J. S. Wainright, O. J. Murphy, and M. R. Antonio, Corros. Sci., 33, 281 (1992).

17. J. Zhao, G. Frankel, and R. L. McCreery, J. Electrochem. Soc., 145, 2258 (1998).

18. N. J. Newhard, Jr., Met. Finish., 70, 49, 66 (1972).

19. L. Xia and McCreery, J. Electrochem. Soc., 146, 3696 (1999).

20. G. O. Ilevbare, J. R. Scully, J. Yuan, and R. G. Kelly, Corrosion (Houston), 56, 227 (2000).

21. G. O. Ilevbare and J. R. Scully, J. Electrochem. Soc., 148, B196 (2001)

22. R. G. Buchheit, M. Cunningham, and H. Jensen, Corrosion (Houston), 54, 61 (1998).

23. A. J. Bard and L. R. Faulkner, Electrochemical Methods: Fundamentals and Applications, John Wiley \& Sons, New York (2001).

24. J. Newman, J. Electrochem. Soc., 113, 501 (1966)

25. T. T. Lunt, V. Brusamarello, J. R. Scully, and J. L. Hudson, Electrochem. SolidState Lett., 3, 271 (2000)

26. Y. Tan, Corros. Sci., 41, 229 (1999).

27. Material Safety Data Sheet for Alodine 1200S, Henkel Corp., Madison Heights, MI. 
28. T. Shibata and T. Takeyama, Corrosion (Houston), 33, 243 (1977).

29. M. W. Kendig, A. J. Davenport, and H. S. Isaacs, Corros. Sci., 34, 41 (1993).

30. J. R. Waldrop and M. W. Kendig, J. Electrochem. Soc., 145, L11 (1998).

31. J. M. Zachara, C. E. Cowan, R. L. Schmidt, and C. C. Ainsworth, Clays Clay Miner., 36(4), 317 (1988).

32. C. H. Weng, J. H. Wang, and C. P. Huang, Water Sci. Technol., 35(7), 55 (1997).

33. C. H. Weng, C. P. Huang, H. E. Allen, P. B. Leavens, and P. F. Sanders, Environ. Sci. Technol., 30, 371 (1996).

34. A. L. Glass, Mater. Prot., 1968, 26 (July).

35. L. Xia, E. Akiyama, G. S. Frankel, and R. L. McCreery, J. Electrochem. Soc., 147, $2556(2000)$

36. G. M. Brown, K. Shimizu, K. Kobayashi, G. E. Thompson, and G. C. Wood,
Corros. Sci., 33, 1371 (1992).

37. P. L. Hagans and C. M. Hass, ASM Handbook, Surface Engineering, Vol. 5, p. 405, ASM International, Metals Park, OH (1994).

38. B. R. W. Hinton, D. R. Arnott, and N. E. Ryan, Met. Forum, 7, 211 (1984).

39. B. R. W. Hinton, J. Alloys Compd., 180, 15 (1992).

40. F. Mansfeld, S. Lin, S. Kim, and H. Shih, Corrosion (Houston), 45, 615 (1989).

41. F. Mansfeld, Y. Wang, and H. Shih, J. Electrochem. Soc., 138, L74 (1991).

42. F. Mansfeld, Y. Wang, and H. Shih, Electrochim. Acta, 37, 2277 (1992).

43. H. Bohni, T. Suter, and A. Schreyer, Electrochim. Acta, 40, 1361 (1995).

44. G. T. Burstein and G. O. Ilevbare, Corros. Sci., 38, 2257 (1996).

45. MIL-C-5541E, Naval Air Engineering Center, Lakehurst, NJ (1990). 